\title{
Intensity of Oestrus Signalling Is the Most Relevant Indicator for Animal Well-Being in High-Producing Dairy Cows
}

\author{
Emanuel Garcia, ${ }^{1}$ Jan Hultgren, ${ }^{1}$ Pontus Fällman, ${ }^{1}$ Johanna Geust, ${ }^{2}$ Bo Algers, ${ }^{1}$ \\ George Stilwell, ${ }^{3}$ Stefan Gunnarsson, ${ }^{1}$ and Heriberto Rodriguez-Martinez ${ }^{1,4}$ \\ ${ }^{1}$ Department of Animal Environment and Health, Swedish University of Agricultural Sciences, 53223 Skara, Sweden \\ ${ }^{2}$ Nötcenter Viken, Vikens Egendom, 52191 Falköping, Sweden \\ ${ }^{3}$ Centro de Investigação Interdisciplinar em Sanidade Animal, Universidade Técnica de Lisboa, 1300-477 Lisboa, Portugal \\ ${ }^{4}$ Department of Clinical and Experimental Medicine, Faculty of Health Sciences, Linköping University, 58185 Linköping, Sweden
}

Correspondence should be addressed to Heriberto Rodriguez-Martinez, heriberto.rodriguez-martinez@liu.se

Received 14 February 2011; Revised 14 June 2011; Accepted 21 June 2011

Academic Editor: Maria Laura Bacci

Copyright ( $) 2011$ Emanuel Garcia et al. This is an open access article distributed under the Creative Commons Attribution License, which permits unrestricted use, distribution, and reproduction in any medium, provided the original work is properly cited.

Full signalling of oestrous behaviour is vital for proper timing of AI and good reproductive performance, currently jeopardized by shorter observations of oestrus behaviour. Alternative indicators including progesterone $\left(\mathrm{P}_{4}\right)$ recordings on-farm are tested. Oestrous intensity of 37 heifers $(\mathrm{H})$ and 30 1st-parity dairy cows $\left(\mathrm{C}_{1}\right)$ either Swedish Red (32) or Swedish Holstein (35) with high genetic potential for milk production, was studied in relation to AI. $\mathrm{P}_{4}$-levels in blood or milk were monitored on-farm at 0,7 , and $20 \mathrm{~d}$ post-AI with a portable ELISA reader $\left(\mathrm{eProCheck}^{800}\right)$. Avoidance distance and body condition were scored at day 7 , and pregnancy diagnosed by $\mathrm{P}_{4}$ (day 20) and trans-rectal palpation (day 50). More heifers (46\%) than $\mathrm{C}_{1}$-cows (10\%) showed standing oestrus (strongest intensity, $P<0.05$ ), leading to higher pregnancy rate at $\mathrm{d} 50$ (72\% versus $37 \%$ for $\mathrm{C} 1, P<0.01$ ) and calving rate $(\mathrm{H}: 64 \%, \mathrm{Cl}: 33 \%, P<0.05)$. Avoidance distances were short $(<1 \mathrm{~m})$, reflecting good human-animal interaction. Visually-recorded standing oestrus yielded 4.8 fold higher odds of pregnancy, respectively 4.6 -fold higher odds of calving. On-farm P4-recordings had complementary value yet less accuracy. Intensity of oestrus signalling relates to animal well-being, reflected in pregnancy-to-term being a good indicator for optimal welfare in high-producing dairy cattle.

\section{Introduction}

Between 1997 and 2007, world milk production increased by $27 \%$ (122 million tonnes) [1]. By 2009, prevailing input costs, alongside the complex worldwide recession, led to a dramatic fall in milk prices [2] and a subsequent decrease in the rate of expected milk production growth [3]. Milk volumes were maintained by a gradually reduced number of high-producing cows. However, high milk production can negatively affect animal welfare $[4,5]$, including the documented global decrease in average dairy herd reproductive performance, mainly in the dominating American Holstein breed. The latter is a backlash of the genetic global use of a limited base of artificial insemination (AI) sires, which, being mainly selected for milk yield but not for health or reproductive traits, have decreased cow robustness in this highly industrialized sector of animal production [6].

Many reproductive disorders reduce, via stress or painful inflammatory reactions, animal welfare at short or long term [4]. In modern dairy farming, signs of standing oestrus are not always displayed or recorded, and they are considered decreasing figures, owing to the concerted action of many factors, primarily due to the inability of the cow to freely display oestrus signs as a consequence of metabolic stress and energy imbalance due to high milk yield and other pathologies (mastitis, lameness, etc.) as well as personnel scarcity [7-9]. Yet neither expression of oestrus nor reproductive performance have been listed as criteria for on-farm welfare assessment [10]. In a large survey performed in Sweden, reproductive performance was, however, ranked 
as a good indicator for animal welfare status in dairy herds [11]. This apparent variation among studies might relate to different conceptual interpretations of the relevance of oestrus signalling for animal well-being and the outcome of breeding.

It is our working hypothesis that optimal behavioural display of oestrus indicates the level of well-being among dairy cattle [12]. Moreover, since full oestrous signals display female receptivity for mating in direct relation to spontaneous ovulation, oestrous intensity would facilitate proper timing for artificial insemination (AI) and, ultimately, affect reproductive performance. Although visual recording is by far the most accurate method to determine presence and intensity of oestrous signs, the restructuring of the dairy sector, with fewer caretakers per number of cattle, has most likely jeopardized proper oestrus detection, leading to improperly timed AI. Complementary methods, such as activity recorders and sophisticated on-line measuring of progesterone $\left(\mathrm{P}_{4}\right)$ levels (reviewed by Rodriguez-Martinez et al. [6]), are being increasingly used instead, particularly in large herds. Whether they can compensate the lack of personnel to visually record oestrous events remains to be determined.

Therefore, we have studied the value of direct observational assessment of oestrous intensity versus relative levels of $\mathrm{P}_{4}$ measured on-farm. We have also determined the relationships between intensity of oestrous signalling with well being indicators (avoidance distance scoring) and reproductive performance (as pregnancy and calving rates). The overall goal was to determine the value of oestrus intensity as a marker for good animal welfare in dairy heifers and first-parity cows with a high genetic potential for milk production.

\section{Material and Methods}

2.1. Ethical Permission. The study was approved in advance by the local Ethics Committee on Animal Research (Dnr 1232008, Gothenburg, Sweden), assuring compliance with EC Directive 86/609/EEC for animal experiments.

2.2. Farm Description: Animals. The study was carried out at the dairy farm Nötcenter Viken (NCV) in Falköping, Sweden. The cattle herd consisted of $\sim 1,000$ heads, including $\sim 400$ milking cows of various parities and $\sim 200$ heifers. Cows were kept in two different parks, separated by breed, whereas heifers were distributed in three contiguous parks in another building. No bulls were present on the farm. The loose housing system at NCV consisted of cubicles equipped with rubber mattresses and concrete-based walkways coated with rubber-mats (cows) or not (heifers). The animals were in-house, except for the compulsory summer grazing period from May to September. Milking took place three times per day $(0500 \mathrm{~h}, 1300 \mathrm{~h}, 2000 \mathrm{~h})$ in a rotary milking parlour (DeLaval, Stockholm, Sweden). A total of 20 employees, working on shift basis, were responsible for managing the animals, including veterinary procedures and the MOET scheme. Animals were fed according to feeding recommendations from Lantmännen (LFU system, 1998 [13]). Basically, rations were composed of grass silage, cereal grains, sugar beet byproducts, and heat-treated rapeseed or soybean meal [13]. Minimum age for first AI was 15 months, and the voluntary waiting period after calving was 50 days. Heat detection was done routinely by NCV AI technicians, by a preliminary recording of activity with the software ALPRO (DeLaval, Stockholm, Sweden, www.delaval.com), followed by a single 1-hour long morning tour within all animal groups, including those in the milking parlour. The study included a total of 37 heifers $(\mathrm{H})$ and 30 first-parity cows ( $\mathrm{C}_{1}$ cows) of either SR (19 heifers, $13 \mathrm{C} 1$-cows) or SH (18 heifers, $17 \mathrm{C} 1$-cows) breeds, varying in body condition (BC), time from parturition, and number of previous AIs.

2.3. Study Design. The study was performed between 13 March and 27 May, 2009. Within the period of study, females identified by the NCV personnel (four AI technicians) to be in oestrus were selected for AI and included in the study, each animal contributing with only one record of AI and a possible pregnancy; that is, animals repeating oestrus did not reenter the study. The day of AI was defined as day 0 (d0). The semen used was from progeny-tested sires, selected based on their genetic background and breeding goals (VikingGenetics, Skara, Sweden), using a standard protocol for thawing (in water at $35^{\circ} \mathrm{C}$ for 12 seconds), and AI (semen deposited in the uterine body). The AI was done on the same day oestrus was detected, up to $1400 \mathrm{~h}$. Milk production records were retrieved until 2 June 2009 to relate average daily milk yield to other variables.

On d0, signs of oestrus were further visually explored by the same independent observer (not NCV personnel) for about an extra morning hour, scoring for presence of mucous vulvar discharge, flehmen reflex, restlessness, licking or sniffing of the perineal region, butting, chin resting, mounted but not standing, mounting other cows (or attempt), and of standing heat. All signs were registered as 0 (absence) or 1 (presence). Restlessness was considered present when the cow showed high activity (ALPRO software recordings) or at visual observation. Signs of oestrus were scored (adapted from Van Eerdenburg et al. [7]) as being of Low intensity (not being mounted and not standing), Medium intensity (being mounted but not standing) or High intensity (standing steadily when mounted). Oestrous scores (OI), complemented with information from the AI technicians regarding ease of $\mathrm{AI}$, and visible metoestrus bleeding, were registered as binary data. Peripheral blood was collected by tail venipuncture after visual assessment using $10 \mathrm{~mL}$ Venosafe vacuum tubes (Venosafe Clot Activator tubes and Venosafe heparin, Vacutainer, Mich, USA), for analysis of the relative contents of progesterone $\left(\mathrm{P}_{4}\right)$ in serum and plasma. Additionally, milk was always collected before blood sampling from cows, also for $\mathrm{P}_{4}$ analysis.

On day $7(\mathrm{~d} 7)$, the inseminated animals were assessed for body condition (BC) and avoidance distance (AD), and blood and milk were once more collected and processed, as described above. BC scoring used the 5-point scale (with 0.5 increments) of the Swedish Dairy Association 
(adapted from Edmonson et al. [14]), and scores were revised using digital images taken from the rear of the cow at a 0 to $20^{\circ}$ angle relative to the tail head as described by Ferguson et al. [15]. The AD was assessed before blood sampling, always by the same person. Each animal was tested twice, at the feeding rack and, immediately thereafter, inside the stall. While feeding, the animals were approached slowly frontwise at one step per second by the observer, one arm overhand in an angle of about $45^{\circ}$ in front of the body, targeting the muzzle, until the cow withdrew or until touching. The distance between the cow's head and the hand was estimated at the moment of withdrawal [16]. In the stall, standing animals were approached from the front and avoidance estimated, as while feeding the proportions of animals that tolerated touch as well as the proportion of animals that allowed touch for more than $3 \mathrm{sec}$ were recorded.

All inseminated animals were visually checked for nonreturn to oestrus in the interval day 18 to day 23. On day 20 (d20), blood and milk were collected and processed, as described above for the inseminated animals. Those animals not returning to oestrus were checked for pregnancy by transrectal palpation on day 50. Events were recorded during pregnancy until partus.

2.4. Progesterone $\left(P_{4}\right)$ Levels in Peripheral Blood Serum/Plasma and Milk. Blood serum was collected after clotting and centrifugation at $300 \times \mathrm{g}$ for $10 \mathrm{~min}$. Blood plasma was collected after centrifugation. Both serum and plasma were transferred to plastic tubes and either analysed immediately after harvesting (serum $n=94$, plasma $n=86$ ) or frozen to $-20^{\circ} \mathrm{C}$ ( serum $n=93$, plasma $n=80$ ) and analysed after thawing at room temperature. Milk, collected into $5 \mathrm{~mL}$ plastic tubes $(n=70)$, was maintained at room temperature for immediate analysis or refrigerated $\left(+4^{\circ} \mathrm{C}\right)$ if the analysis was delayed for more than $15 \mathrm{~min}$. Milk samples were analysed within $4 \mathrm{~h}$ of sampling following manual shacking (10 times).

An enzyme-linked immunosorbent assay (ELISA) test, run in the eProCheck ${ }^{800}$ processor (Minitüb, Tiefenbach, Germany [17]) was used to determine relative $\mathrm{P}_{4}$ levels in blood serum, blood plasma, or milk. Samples measured were $15 \mu \mathrm{L}$ for serum or plasma or $20-30 \mu \mathrm{L}$ for milk, allowing 1 to 7 samples to be tested at a time within a 20 -minute analysis. Once loaded to the sample vial of the reader, the vial holder was inserted into the device, and the following procedures were automatically conducted: addition of conjugate, incubation, wash, addition of enzyme-substrate complex, incubation, and results output. $\mathrm{P}_{4}$ concentration was evaluated in the device by colour change, and from 1 to 7 samples could be tested at a time within a 20 -minute analysis. The results of relative $\mathrm{P}_{4}$ levels were given by the processor as a bar graph with 6 levels (1-6), which, according to the manufacturer [17], corresponded to the following $\mathrm{P}_{4}$ concentration ranges (in $\mathrm{nM} / \mathrm{L}$ ): 1: $0-1.3,2: 1.4-3.0,3: 3.1$ 4.5, 4: 4.6-7.5, 5: 7.6-9.9, 6: >10, and which could be grouped as Low (levels 1-2, <3.0 nM/L), Medium (levels 3-4, 3.1$7.5 \mathrm{nM} / \mathrm{L}$ ) or High (levels 5-6, >7.6 nM/L).
2.5. Statistical Analysis. The data were analysed using the SAS statistical package, version 9.1 for Windows (SAS Institute Inc., Cary, NC, USA). Spearman rank correlation analysis was used to determine relationships between variables. Differences in mean values and proportions were, respectively, examined with $t$-test (age, BCS, AD) and Fisher's exact test (category, breed, OI, lameness, pregnancy and calving rates) while the Kruskal-Wallis test was used for pairwise comparisons. Analysis of variance (ANOVA) using the General Linear Models procedure with Tukey adjustment was used for comparison of avoidance distance in different OIs and $\mathrm{P}_{4}$ on day 7 . Odd ratios were derived from a contingency table. Differences of $P<0.05$ were considered statistically significant.

\section{Results}

The studied population (37 heifers and $30 \mathrm{C}_{1}$-cows) was rather evenly distributed by breed (Heifers: $\mathrm{SH}-49 \%$ and SR-51\%, C 1 -cows: SH-57\% and SR-43\%), with clear age differences (Heifers: $18 \pm 2.2$ (means \pm SD, range 15-24) compared to $C_{1}$ cows: $33.5 \pm 7.0$ (27-55), $P<0.01$ ). Prevalence of BCS differed significantly $(P<0.05)$ between categories (Heifers: $3.4 \pm 0.4$ (points, range 2.5-4), $\mathrm{C}_{1}$-cows: $2.8 \pm 0.4 \mathrm{~b}(2-3.5))$. Average milk production per day for the $\mathrm{C}_{1}$ cows within the study period was $33.4 \pm 5.2 \mathrm{~kg}$ (means \pm $\mathrm{SD})$.

Intra- and interassay comparisons were done (see Table 1) with CVs being below 5\%, particularly when the relative $\mathrm{P}_{4}$ levels in the samples were extreme (either High $[5,6]$ or Low $[1,2])$. Comparison of paired samples of various sources (plasma, serum, or milk) with the same relative $\mathrm{P}_{4}$ level (Low, Medium, or High) showed that serum versus plasma had the highest degree of similarity $(73.2 \%$ of samples had the same $\mathrm{P}_{4}$ level, $n=224,95 \% \mathrm{CI}=67.9$ $78.1 \%)$, followed by plasma versus milk (65.4\% same $\mathrm{P}_{4}$ level, $n=81,95 \% \mathrm{CI}=55.8-74.2 \%$ ), and lastly, serum versus milk (55.6\% same $\mathrm{P}_{4}$-level, $n=81,95 \% \mathrm{CI}=45.8-65.0 \%$ ). The most consistent sample volumes were $15 \mu \mathrm{L}$ for blood plasma or serum (either fresh or frozen) and $20 \mu \mathrm{L}$ for milk.

Low, Medium, or High oestrous intensity (OI) was shown by $33(49 \%), 14(21 \%)$, or $20(30 \%)$ of the 67 animals studied (heifers and $\mathrm{C}_{1}$-cows) at $\mathrm{d} 0$. Oestrous intensity was more often scored as High among heifers (17/37) than among $\mathrm{C}_{1}$ cows $(3 / 30)(P<0.01)$. For Low oestrous signs, however, there were no differences between animal categories (NS, $P>0.05$ ). When observations were stratified by $\mathrm{OI}$, animal category (heifers or $\mathrm{C}_{1}$-cows), and breed (SR or $\mathrm{SH}$ ), there were no significant differences in relative $\mathrm{P}_{4}$ levels in blood serum at d0 (not significant, NS) (Table 2). Furthermore, there were no differences when comparing extreme oestrous intensity levels, that is, Low versus High, regarding proportions of the three $\mathrm{P}_{4}$ levels (not NS), indicating that oestrous intensity and relative $\mathrm{P}_{4}$ levels in peripheral blood were unrelated (Table 2). The $\mathrm{P}_{4}$ levels in peripheral blood varied widely. Relative $\mathrm{P}_{4}$ serum level at day 0 was Low in $47 \%$ of all studied animals (31/67 animals, 95\% CI = $65-83 \%)$, while $31 \%$ (20/67 animals, 95\% CI $=22-41 \%)$ 
TABLE 1: Intra- and interassay measurements of relative $\mathrm{P}_{4}$ concentrations [low (levels 1-2, $<3.0 \mathrm{nM} / \mathrm{L}$ ), medium (levels 3-4, 3.1-7.5 nM/L) or high (levels 5-6,>7.6 nM/L)), studied in fresh serum, plasma, or milk, or frozen-thawed serum or plasma samples, comparing different sample volumes, at various days (day 0,7 , or 20 ) of AI, provided by the eProCheck ${ }^{800}$. Number of observations per sample and coefficient of variation $(\mathrm{CV})$ are indicated.

\begin{tabular}{|c|c|c|c|c|c|c|c|c|c|c|c|}
\hline \multirow{4}{*}{$\begin{array}{l}\text { Sample status } \\
\text { Day sampled } \\
\text { Sample type } \\
\end{array}$} & \multicolumn{8}{|c|}{ Intraassay } & \multicolumn{3}{|c|}{ Interassay } \\
\hline & \multicolumn{4}{|c|}{ Fresh } & \multicolumn{4}{|c|}{ Frozen-thawed } & \multirow{3}{*}{$\begin{array}{c}\text { Fresh } \\
\text { d0 } \\
\text { Serum } \\
\end{array}$} & \multicolumn{2}{|c|}{ Frozen-thawed } \\
\hline & \multirow{2}{*}{$\begin{array}{c}\mathrm{d} 0 \\
\text { Serum }\end{array}$} & \multirow{2}{*}{$\begin{array}{c}\text { d20 } \\
\text { Plasma }\end{array}$} & \multirow{2}{*}{$\begin{array}{c}\text { d0 } \\
\text { Milk }\end{array}$} & \multirow{2}{*}{$\begin{array}{c}\text { d7 } \\
\text { Milk }\end{array}$} & \multicolumn{2}{|c|}{ d0 } & \multicolumn{2}{|c|}{$\mathrm{d} 20$} & & \multirow{2}{*}{$\begin{array}{c}\text { d0 } \\
\text { Serum } \\
\end{array}$} & \multirow{2}{*}{$\begin{array}{c}\mathrm{d} 0 \\
\text { plasma }\end{array}$} \\
\hline & & & & & Serum & Plasma & Serum & Plasma & & & \\
\hline Sample size, $\mu \mathrm{L}$ & 15 & 15 & 30 & 20 & 15 & 15 & 15 & 15 & 15 & 15 & 15 \\
\hline $\begin{array}{l}\text { No. of } \\
\text { replicates }\end{array}$ & 5 & 10 & 10 & 7 & 7 & 7 & 7 & 7 & 7 & 6 & 7 \\
\hline Replicates & & & & & & $\mathrm{P}_{4}$-Le & & & & & \\
\hline 1 & low & med & low & high & med & high & high & high & low & low & high \\
\hline 2 & low & med & med & high & high & high & high & high & low & low & high \\
\hline 3 & low & med & low & high & med & high & high & high & low & low & high \\
\hline 4 & low & high & med & high & high & high & high & high & med & low & high \\
\hline 5 & low & med & low & high & med & high & high & high & low & low & high \\
\hline 6 & & med & med & high & med & high & high & high & low & low & high \\
\hline 7 & & med & med & high & high & med & high & high & low & low & high \\
\hline 8 & & med & low & & & & & high & & & \\
\hline 9 & & med & med & & & & & & & & \\
\hline 10 & & med & low & & & & & & & & \\
\hline CV (\%) & $<5.0$ & 15.1 & 35.1 & $<5.0$ & 22.0 & 13.2 & $<5.0$ & $<5.0$ & 33.1 & $<5.0$ & $<5.0$ \\
\hline
\end{tabular}

were Medium and 24\% (16/67 animals, 95\% CI = 16-34\%) were High. Comparing categories of animals, only $\mathrm{C}_{1}$-cows showed a trend in the relationship between oestrous intensity and $\mathrm{P}_{4}$ levels, albeit being nonsignificant (NS), irrespective of breed. The distribution of animals having Low $\mathrm{P}_{4}$ levels at d0 did not vary significantly (NS) among the four oestrusdetecting technicians.

The avoidance distance tested either at the feeding rack or the stall yielded different distances in $\mathrm{C}_{1}$-cows than in heifers (30 versus $47 \mathrm{~cm}$ or 83 versus $103 \mathrm{~cm}$, resp., NS), without a clear breed effect. There was a reasonable correlation between avoidance distances at the feeding rack and installs $(r=0.45$, $P<0.001)$. The avoidance distance means were apparently shorter, although nonsignificant (NS), in animals having depicted High oestrous intensity. At the feeding rack, up to $35 \%(22 / 62)$ of the animals tolerated touch, of which $9(15 \%)$ were heifers and $13(21 \%)$ were C1-cows. Up to $27 \%(6 / 22)$ of animals could be touched for more than 3 seconds, $22 \%$ $(2 / 9)$ of heifers and $31 \%$ (4/13) of cows. Finally, $11 \%$ of the $\mathrm{C}_{1}$-cows $(3 / 27)$ tolerated being touched in the stalls, but none of them for more than 3 seconds. Cow age correlated positively with avoidance distance at the feeding rack $(r=$ 0.57). Comparing the two locations for avoidance distance assessment, there was a moderate positive correlation $(r=$ $0.49, P<0.05$ ), confirming to some degree the concordance of the procedures. One heifer had to be euthanised due to severe lesions after an accident in the stall and the data were removed from further analyses.

Overall pregnancy rate at d50 was 56\% (37/66 animals), while overall calving rate reached 50\% (33/66 animals). Up to $80 \%$ of the animals depicting High oestrous intensity became pregnant, compared to $45 \%$ depicting Low oestrous intensity at $\mathrm{d} 0(P<0.05)$, whereas $46 \%$ of those depicting Medium intensity did not differ significantly from High or Low. Higher oestrous intensity related significantly to higher pregnancy $(r=0.28, P<0.05)$. As expected, heifers had a higher pregnancy rate than $\mathrm{C} 1$-cows, $72 \%$ versus $37 \%$ $(P<0.01$, Table 3$)$. This difference was maintained for calving rates $(64 \%$ versus $33 \%(P<0.05$, Table 3$)$. Standing oestrus was associated with 4.8 - and 4.6-fold higher odds of pregnancy calving, respectively. Pregnancy rate was highest among heifers with a low $\mathrm{P}_{4}$ level at $\mathrm{d} 0(80 \%)$, but it was considerably lower in corresponding C1-cows $(31 \%)(P<$ 0.01 , Table 3$)$. Calving rates maintained the trends shown by pregnancy rate at $\mathrm{d} 50$ (Table 3 ). As expected, there was a strong correlation between $\mathrm{P}_{4}$ level at $\mathrm{d} 20$ and pregnancy rate $(r=0.55, P<0.0001)$. The odds of females that showed standing oestrus (High) becoming pregnant, respectively, calving were 4.8 - and 4.6-fold, respectively, higher (95\% CI $=1.38-16.45$ resp., $95 \%$ CI $=1.44-15.08)$ than for females showing only secondary oestrous signs (LowMedium). Some animals became pregnant and subsequently calved despite a recorded high $\mathrm{P}_{4}$ level at d0 (6/11 heifers and $3 / 6 \mathrm{C} 1$-cows). Considering $\mathrm{C}_{1}$-cows, the older the animal, the lower the oestrous intensity $(r=-0.42, P<0.05)$.

\section{Discussion}

The present study determined the presence of associations between intensity of oestrus signs and $\mathrm{P}_{4}$ levels in peripheral blood or milk with pregnancy-to-term outcome after AI and behavioural indices (avoidance distance testing), in 
TABLE 2: Distribution (frequency and \%) of dairy cattle according to oestrous intensity and relative progesterone $\left(\mathrm{P}_{4}\right)$ levels in blood serum on day 0 for all animals, as well as disclosed by category (dairy heifers (H) or first-parity cows (C1 cows)) or breed (Swedish Holstein SH or Swedish Red SR including both $\mathrm{H}$ and C1 cows).

\begin{tabular}{|c|c|c|c|c|c|c|c|c|c|}
\hline & \multicolumn{9}{|c|}{ Oestrous intensity } \\
\hline & \multicolumn{3}{|c|}{ Low } & \multirow{2}{*}{\multicolumn{3}{|c|}{$\begin{array}{c}\text { Medium } \\
\text { Progesterone at do }\end{array}$}} & \multirow{2}{*}{\multicolumn{3}{|c|}{ High }} \\
\hline & & & & & & & & & \\
\hline & Low & Medium & High & Low & Medium & High & Low & Medium & High \\
\hline All (67) & $\begin{array}{l}14 / 33 \\
(42)^{\mathrm{ab}}\end{array}$ & $9 / 33(27)^{\mathrm{ab}}$ & $9 / 32(28)^{\mathrm{ab}}$ & $8 / 14(57)^{\mathrm{a}}$ & $3 / 14(21)^{\mathrm{ab}}$ & $3 / 14(21)^{\mathrm{ab}}$ & $9 / 20(45)^{\mathrm{a}}$ & $8 / 20(40)^{\mathrm{a}}$ & $3 / 20(15)^{b}$ \\
\hline Heifers (37) & $7 / 15(47)^{\mathrm{a}}$ & $3 / 15(20)^{\mathrm{a}}$ & $4 / 14(29)^{\mathrm{a}}$ & $2 / 5(40)^{\mathrm{a}}$ & $1 / 5(20)^{\mathrm{a}}$ & $2 / 5(40)^{\mathrm{a}}$ & $6 / 17(35)^{\mathrm{a}}$ & $8 / 17(47)^{\mathrm{a}}$ & $3 / 17(18)^{\mathrm{a}}$ \\
\hline $\mathrm{C} 1$ cows $(30)$ & $7 / 18(39)^{a}$ & $6 / 18(33)^{a}$ & $5 / 18(28)^{\mathrm{a}}$ & $6 / 9(67)^{a}$ & $2 / 9(22)^{\mathrm{a}}$ & $1 / 9(11)^{\mathrm{a}}$ & $3 / 3(100)^{\mathrm{a}}$ & - & - \\
\hline SH (36) & $8 / 16(50)^{a}$ & $5 / 16(31)^{a}$ & $3 / 16(19)^{a}$ & $4 / 7(57)^{\mathrm{a}}$ & $1 / 7(14)^{\mathrm{a}}$ & $2 / 7(29)^{\mathrm{a}}$ & $7 / 13(54)^{a}$ & $3 / 13(23)^{a}$ & $2 / 12(17)^{\mathrm{a}}$ \\
\hline $\operatorname{SR}(31)$ & $6 / 17(35)^{\mathrm{a}}$ & $4 / 17(24)^{\mathrm{a}}$ & $7 / 17(41)^{\mathrm{a}}$ & $4 / 7(57)^{\mathrm{a}}$ & $2 / 7(29)^{\mathrm{a}}$ & $1 / 7(14)^{\mathrm{a}}$ & $2 / 8(25)^{\mathrm{a}}$ & $5 / 8(63)^{\mathrm{a}}$ & $1 / 8(13)^{\mathrm{a}}$ \\
\hline
\end{tabular}

${ }_{\mathrm{a}, \mathrm{b}}$ different superscripts differ significantly, $\mathrm{P}<0.05$ (Fisher's exact test), between $\mathrm{P}_{4}$ (all animals) and between animal category ( $\mathrm{H}$ and $\left.\mathrm{C} 1\right)$ and breed (SH and SR), for $\mathrm{P}_{4}$ within oestrous intensity level.

TABle 3: Percentages of pregnancy (animal ratios in parentheses) at day 50 (transrectal manual examination) and of calving, disclosed by relative $\mathrm{P}_{4}$ level in blood serum on day 0 and by intensity of oestrus (day 0$)$ for dairy Heifers $(n=37)$ or first parity cows (C1 cows, $n=30$ ).

\begin{tabular}{|c|c|c|c|c|c|c|c|c|}
\hline \multirow[t]{2}{*}{ Animal category } & \multirow[t]{2}{*}{$\mathrm{P}_{4}$ at day 0} & \multicolumn{3}{|c|}{ Oestrous intensity at day 0} & \multicolumn{2}{|c|}{ Pregnancy rates } & \multicolumn{2}{|c|}{ Calving rates } \\
\hline & & Low & Medium & High & & & & \\
\hline \multirow{3}{*}{ Heifers } & Low & $71(5 / 7)$ & $50(1 / 2)$ & $100(6 / 6)$ & $80^{\mathrm{a}}(12 / 15)$ & & $60(9 / 15)$ & \\
\hline & Medium & $67(2 / 3)$ & $0(0 / 1)$ & $75(6 / 8)$ & $67^{\mathrm{ab}}(8 / 12)$ & $72^{a}(26 / 36)$ & $58(7 / 12)$ & $64^{\mathrm{a}}(23 / 36)$ \\
\hline & High & $60(3 / 5)$ & $100(1 / 1)$ & $672 / 3$ & $67^{\mathrm{ab}}(6 / 9)$ & & $78(7 / 9)$ & \\
\hline \multirow{3}{*}{ C1 cows } & Low & $14(1 / 7)$ & $33(2 / 6)$ & $67(2 / 3)$ & $31^{\mathrm{b}}(5 / 16)$ & & $25(4 / 16)$ & \\
\hline & Medium & $33(2 / 6)$ & $50(1 / 2)$ & - & $38^{\mathrm{ab}}(3 / 8)$ & $37^{\mathrm{b}}(11 / 30)$ & $38(3 / 8)$ & $33^{\mathrm{b}}(10 / 30)$ \\
\hline & High & $40(2 / 5)$ & $100(1 / 1)$ & - & $50^{\mathrm{ab}}(3 / 6)$ & & $50(3 / 6)$ & \\
\hline \multicolumn{2}{|c|}{ Pregnancy rates } & $45^{\mathrm{a}}(15 / 33)$ & $46^{\mathrm{ab}}(6 / 13)$ & $80^{\mathrm{b}}(16 / 20)$ & 56 & /66) & & \\
\hline \multicolumn{2}{|c|}{ Calving rates } & $39^{a}(13 / 33)$ & $38^{\mathrm{a}}(5 / 13)$ & $75^{\mathrm{b}}(15 / 20)$ & & & \multicolumn{2}{|c|}{$50(33 / 66)$} \\
\hline
\end{tabular}

$\overline{\mathrm{a}, \mathrm{b}}$ different superscripts differ significantly between animal categories $(P<0.01$ on PR column and $P<0.05$ on CR column, PR row and CR row).

Swedish Holstein or Swedish Red heifers and first-parity (C1) cows with high genetic potential for milk yield in a single nucleus herd having the same management and feeding routines. Overall pregnancy and calving rates $(56 \%$ and $50 \%$, resp.) were acceptable, with heifers having higher rates than $\mathrm{C} 1$ cows. Highest oestrous signalling was reflected in higher pregnancy/calving rates, standing oestrus having 4.8to-4.6-fold higher odds of pregnancy calving, respectively, compared to detection based on secondary oestrus signs. Avoidance distance means (at either the feeding rack or the stall) were generally short $(<1 \mathrm{~m})$, but without significant relationship with oestrous intensity.

As expected, C1 cows depicted a lower OI display than heifers, which could be due to differences in housing, management, or incidence of lameness [9]. Further, the higher the intensity of oestrus, the higher the pregnancy and calving rates achieved $(80 \%$, and $75 \%$, resp.). This finding is in agreement with Van Eerdenburg et al. [7], who found a shorter interval to ovulation $(<24 \mathrm{~h})$ in cows that scored (almost three times) higher intensity of oestrus. In the present study, pregnant animals scored higher than nonpregnant ones, clearly indicating that standing oestrus (as a token for full physiological signalling display) is still the best behavioural marker for successful AI. There is a trend in current dairy production for a decreased expression of oestrous signs [6]. This, together with increasing numbers of larger herds but with less personnel, led to an increased use of secondary signs, without standing heat or even hormonal measurements $\left(\right.$ as $\left.\mathrm{P}_{4}\right)$ to help decide when $\mathrm{AI}$ is to be performed. Oestrus of lower intensity is associated with delayed ovulation, reduced preovulatory oestradiol $\left(\mathrm{E}_{2}\right)$ concentration, and poorer oocyte quality [18]. Obviously, it is of utmost importance to determine what causes low oestrous display.

The eProCheck ${ }^{800}$ automated ELISA reader primarily appeared to complement usual on-farm reproductive management, being able to determine $\mathrm{P}_{4}$ relative levels in most samples analysed either fresh (milk, serum, plasma) or frozen-thawed (serum, plasma). The highest degree of accuracy was for extreme values, for example, Low $(<3.1 \mathrm{nM} / \mathrm{L})$ or High $(>7.6 \mathrm{mM} / \mathrm{L}) \mathrm{P}_{4}$ concentrations, but variability was highest when milk was tested, suggesting that the instrument best analysed serum or plasma samples. However, for practical reasons, milk samples are easiest to retrieve under commercial conditions, and, thus, the instrument should preferably be adapted to this type of samples.

The decisions to breed were based solely on routine oestrus determinations by the personnel at Nötcenter Viken 
(NCV). Interestingly, if decisions had instead been based on $\mathrm{P}_{4}$ serum levels at $\mathrm{d} 0$, only $46 \%$ of the animals ought to have been inseminated; $59 \%$ if based on blood plasma and $90 \%$ if based on milk. However, nine animals with high $\mathrm{P}_{4}$ levels in blood serum became pregnant and calved, owing to either inaccurate readings or wrongly identified samples. Despite this flaw, the overall pregnancy rate in the animals studied did not differ substantially from what would have been obtained if breeding decisions had been based solely on eProCheck ${ }^{800}$ serum readings (55\%), also when looking separately at heifers (72\% versus $80 \%)$ and $\mathrm{C}_{1}$-cows (31\% versus $37 \%)$. However, the number of inseminated animals would have been rather low, which makes us refrain from stronger conclusions. Considering a relative $\mathrm{P}_{4}$ level of $>10 \mathrm{nM} / \mathrm{L}$ in serum, plasma, or milk as the true value on $\mathrm{d} 20$ in a pregnant cow resulted in a sensitivity estimate of the eProCheck ${ }^{800}$ of $97 \%, 92 \%$, and $89 \%$, respectively, and a specificity of $50 \%, 60 \%$, and $75 \%$, respectively. An alternative measure of accuracy was defined from a practical perspective, considering an animal as truly nonpregnant only if having a higher $\mathrm{P}_{4}$ level on $\mathrm{d} 7$ than on $\mathrm{d} 20$. This approach generated corresponding specificity estimates of $40 \%, 57 \%$, and $46 \%$, respectively. The eProCheck ${ }^{800}$ will hopefully be continuously upgraded to improve its accuracy.

The complete behavioural repertoire of oestrous display was observed in the studied animal population, except for the flehmen reflex (seen in other animals in the herd), and so the plurality of oestrous expression did not seem to be negatively affected. Oestrous intensity was classified as Low (slight signs) in almost half of the studied sample, while the other half accounted for Medium (21\% of animals were mounted but not standing; mounting) or High (30\% of animals showed standing oestrus) oestrous intensities, respectively. At first sight, this low display of strong oestrous intensity might result in a threat to fertility, especially if detection of oestrus is not optimized. Since the van Eerdenburg et al. [7] scoring system used here, albeit with slight modifications, clearly evidenced differences between heifers and $C_{1}$ cows, it would be advisable to include it as routine at NCV. Oestrous intensity was lower in $\mathrm{C}_{1}$-cows compared to heifers, confirming the negative influence that high milk yield imposes, particularly among first calvers [6]. Although negative correlations were found between oestrous intensity variables and milk production in the present study, analysis of the whole lactation would be needed to draw more accurate conclusions. Moreover, the low variability in average milk production per day for the $\mathrm{C}_{1}$-cows within the study period $(33.4 \pm 5.2 \mathrm{~kg}$, mean $\pm \mathrm{SD})$, probably resulting from the high genetic potential for milk production of the animals studied within the NCV herd, might have contributed to the inconclusive results.

Avoidance distance was shorter in $\mathrm{C}_{1}$-cows than in heifers, which probably should be explained by a good human-animal relationship, particularly owing to caretaker attitudes during milking and to the intensity of management and high number of caretakers [16]. Therefore, our findings ought to be considered for this particular farm/herd, as it should for the finding that in $\mathrm{C}_{1}$-cows, age correlated strongly with $\mathrm{AD}$, contrary to the findings of Waiblinger et al. [16] who included several herds. Estimates of avoidance distance at the feeding rack and within the stall correlated moderately, in contrast to Windschnurer et al. [19] who found a stronger correlation $(r=0.7-0.9)$ in a study on 16 commercial dairy farms. Waiblinger et al. [16] found a strong relationship between animals' reactions to humans, particularly avoidance distance inside the stall and the continuity, quality, and quantity of daily contact and handling, and the frequency of friendly interactions with the person milking them (human-animal interactions). Other authors also revealed negative associations between avoidance distances and positive behaviour of milkers on dairy farms and of farmers at bull fattening operations [20, 21]. Accordingly, there is evidence that positive interactions ease handling and milking, increase productivity, and can reduce prevalence of mastitis by promoting adequate milk flow, which has, in additional to improved welfare, an economic impact [4].

The relationship between avoidance distance and oestrous intensity was statistically nonsignificant. No other scientific publication has, to the best of our knowledge, related oestrous intensity with avoidance distance. Possibly, an animal with a good welfare status and, so, properly adapted to its environment, would have a short avoidance distance and, being in a normal physiological state, would have an intense (normal) oestrus. However, avoidance distance cannot be evaluated separately from other welfare criteria. Whay et al. [22] developed a protocol for avoidance distance testing, which would have scored NCV as the first of five categories, with the shortest distances $(0.6-1.1 \mathrm{~m})$. Programmes that aim to improve the attitude and behaviour of stockpersons toward dairy cattle can reduce flight distances from humans and increase milk (protein and fat) yields (reviewed by $[4,23])$.

Pregnancy respectively calving rates were acceptable for heifers (72\%, resp., 64\%), but they were rather low among $\mathrm{C}_{1}$ cows $(37 \%$, resp., 33\%). Low fertility is largely attributed to the increase in milk production due to genetic gain, which can explain a part of the low fertility seen in the primiparous cows in the present study [6]. Despite the fact that four heifers-three of them of the $\mathrm{SH}$ breed suffered abortions, the calving results of the present study do not seem to be as poor, particularly for heifers. Whether differences in genetic selection in Scandinavia compared to other regions/countries lay behind the better calving rates for heifers in this herd remains to be determined (see [6]). On the other hand, the low rates depicted by $\mathrm{C}_{1}$-cows included in this study deserve attention and further investigation, particularly in relation to AI timing. Attention should be given to individuals with extreme body condition scores, particularly to heifers with high body weight, since they are at risk of becoming problem animals, incurring in repeat breeding (see [6], and references therein).

\section{Conclusions}

Odds of pregnancy-to-term outcome are several times higher when standing oestrus is observed than when animals display only secondary oestrous signs. Monitoring $\mathrm{P}_{4}$ levels on-farm 
could not replace intensive visual detection of oestrus in relation to animal well-being, although avoidance distance was not necessarily related to oestrous intensity.

\section{Acknowledgments}

The authors wish to thank Dipl. Ing. Agr. Eva Haeusler (Minitüb Germany) and the staff of Nötcenter Viken (Falköping, Sweden) for assistance during the execution of this work.

\section{References}

[1] International Dairy Federation, "The world dairy situation 2008," Bulletin of the IDF, no. 432/2008, International Dairy Federation, Brussels, Kingdom of Belgium, 2008.

[2] International Dairy Federation, IDF Leaders Brief, no. 6, International Dairy Federation, Brussels, Kingdom of Belgium, 2009.

[3] International Dairy Federation, "The scientific expertise for the dairy sector worldwide," IDF Newsbrief, no. 70, International Dairy Federation, Brussels, Kingdom of Belgium, 2009.

[4] European Food Safety Authority (EFSA), "Scientific report of EFSA prepared by the Animal Health and Animal Welfare Unit on the effects of farming systems on dairy cow welfare and disease," Annex to the EFSA Journal, vol. 1143, pp. 1-284, 2009.

[5] P. A. Oltenacu and B. Algers, "Selection for increased production and the welfare of dairy cows: are new breeding goals needed?" Ambio, vol. 34, no. 4-5, pp. 311-315, 2005.

[6] H. Rodriguez-Martinez, J. Hultgren, R. Båge et al., "Reproductive performance in high-producing dairy cows: can we sustain it under current practice?" in International Veterinary Information Service, IVIS Reviews in Veterinary Medicine, IVIS, Ithaca, NY, USA, 2008, http://www.ivis.org/ signin.asp?url=/reviews/rev/rodriguez/chapter.asp?la=1.

[7] F. J. C. M. Van Eerdenburg, D. Karthaus, M. A. M. Taverne, I. Merics, and O. Szenci, "The relationship between estrous behavioral score and time of ovulation in dairy cattle," Journal of Dairy Science, vol. 85, no. 5, pp. 1150-1156, 2002.

[8] M. G. Diskin, "Reproductive management of dairy cows: a review (part I)," Irish Veterinary Journal, vol. 61, no. 5, pp. 326-332, 2008.

[9] E. Garcia, J. Hultgren, P. Fällman et al., "Oestrous intensity is positively associated with reproductive outcome in highproducing dairy cows," Livestock Science, vol. 139, no. 3, pp. 191-195, 2011.

[10] Welfare Quality®, Welfare Quality®: Assessment Protocol for Cattle, Welfare Qualityß Consortium, Lelystad, The Netherlands, 2009.

[11] C. H. Sandgren, A. Lindberg, and L. J. Keeling, "Using a national dairy database to identify herds with poor welfare," Animal Welfare, vol. 18, no. 4, pp. 523-532, 2009.

[12] Farm Animal Welfare Council, "Farm Animal Welfare Council: five freedoms," June 2009, http://www.fawc.org.uk /freedoms.htm.

[13] M. Murphy, "Making the most of grass-based forages in diet formulation," Advanced Dairy Technology, vol. 16, pp. 205215, 2004.

[14] A. Edmonson, I. Lean, L. Weaver, T. Farver, and G. Webster, "A body condition scoring chart for Holstein dairy cows," Journal of Dairy Science, vol. 72, pp. 68-78, 1989.
[15] J. D. Ferguson, G. Azzaro, and G. Licitra, "Body condition assessment using digital images," Journal of Dairy Science, vol. 89, no. 10, pp. 3833-3841, 2006.

[16] S. Waiblinger, C. Menke, and D. W. Fölsch, "Influences on the avoidance and approach behaviour of dairy cows towards humans on 35 farms," Applied Animal Behaviour Science, vol. 84 , no. 1, pp. 23-39, 2003.

[17] Minitüb, eProCheck (leaflet), Minitüb, Tiefenbach, Germany, 2008.

[18] E. Cutullic, L. Delaby, D. Causeur, G. Michel, and C. Disenhaus, "Hierarchy of factors affecting behavioural signs used for oestrus detection of Holstein and Normande dairy cows in a seasonal calving system," Animal Reproduction Science, vol. 113, no. 1-4, pp. 22-37, 2009.

[19] I. Windschnurer, C. Schmied, X. Boivin, and S. Waiblinger, "Reliability and inter-test relationship of tests for on-farm assessment of dairy cows' relationship to humans," Applied Animal Behaviour Science, vol. 114, no. 1-2, pp. 37-53, 2008.

[20] P. H. Hemsworth, G. J. Coleman, J. L. Barnett, and S. Borg, "Relationships between human-animal interactions and productivity of commercial dairy cows," Journal of Animal Science, vol. 78, no. 11, pp. 2821-2831, 2000.

[21] I. Windschnurer, X. Boivin, and S. Waiblinger, "Reliability of an avoidance distance test for the assessment of animals' responsiveness to humans and a preliminary investigation of its association with farmers' attitudes on bull fattening farms," Applied Animal Behaviour Science, vol. 117, no. 3-4, pp. 117127, 2009.

[22] H. R. Whay, D. C. J. Main, L. E. Green, and A. J. F. Webster, "Assessment of the welfare of dairy cattle using animal-based measurements: direct observations and investigation of farm records," Veterinary Record, vol. 153, no. 7, pp. 197-202, 2003.

[23] P. H. Hemsworth, G. J. Coleman, J. L. Barnett, S. Borg, and S. Dowling, "The effects of cognitive behavioral intervention on the attitude and behavior of stockpersons and the behavior and productivity of commercial dairy cows," Journal of Animal Science, vol. 80, no. 1, pp. 68-78, 2002. 

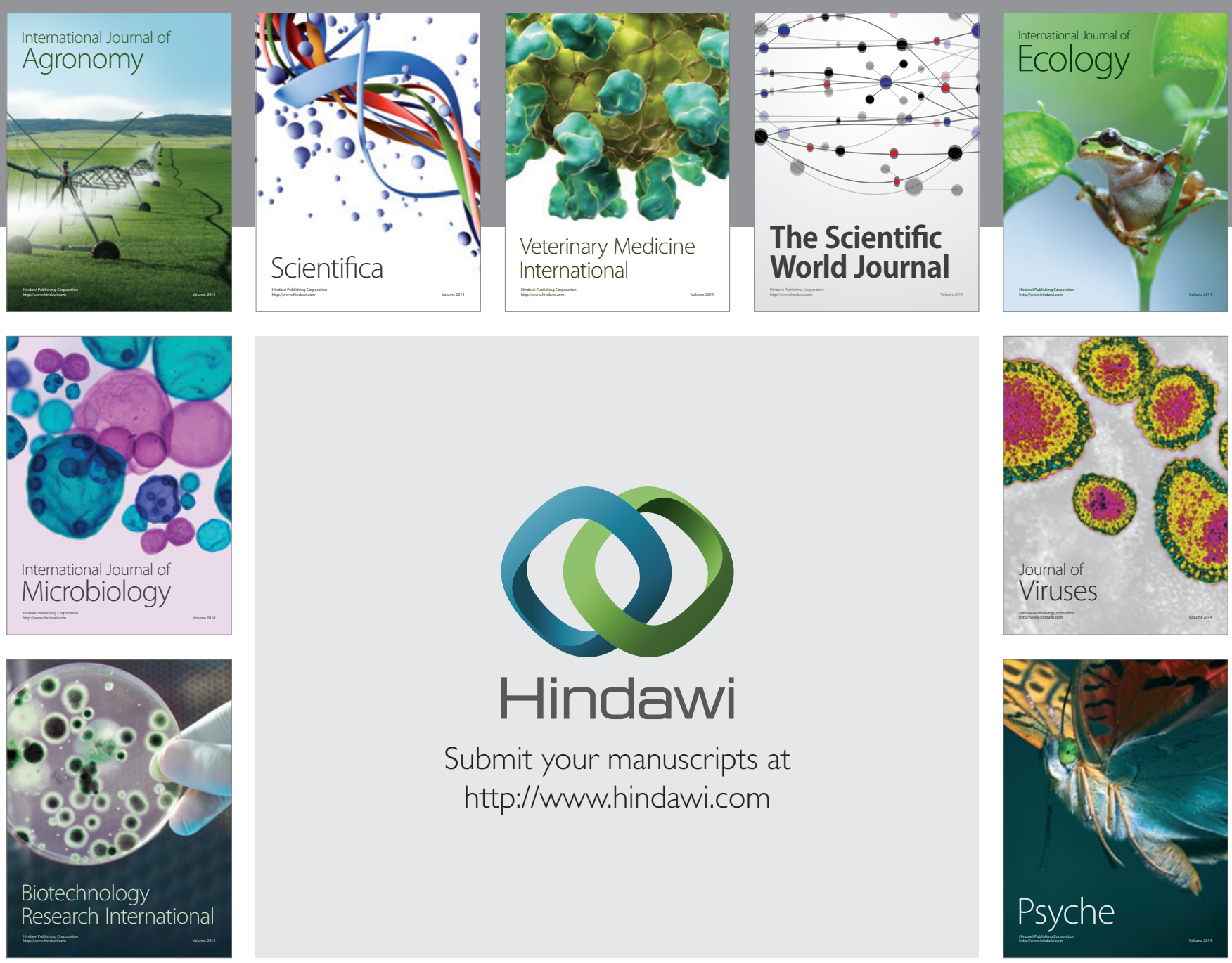

Submit your manuscripts at

http://www.hindawi.com
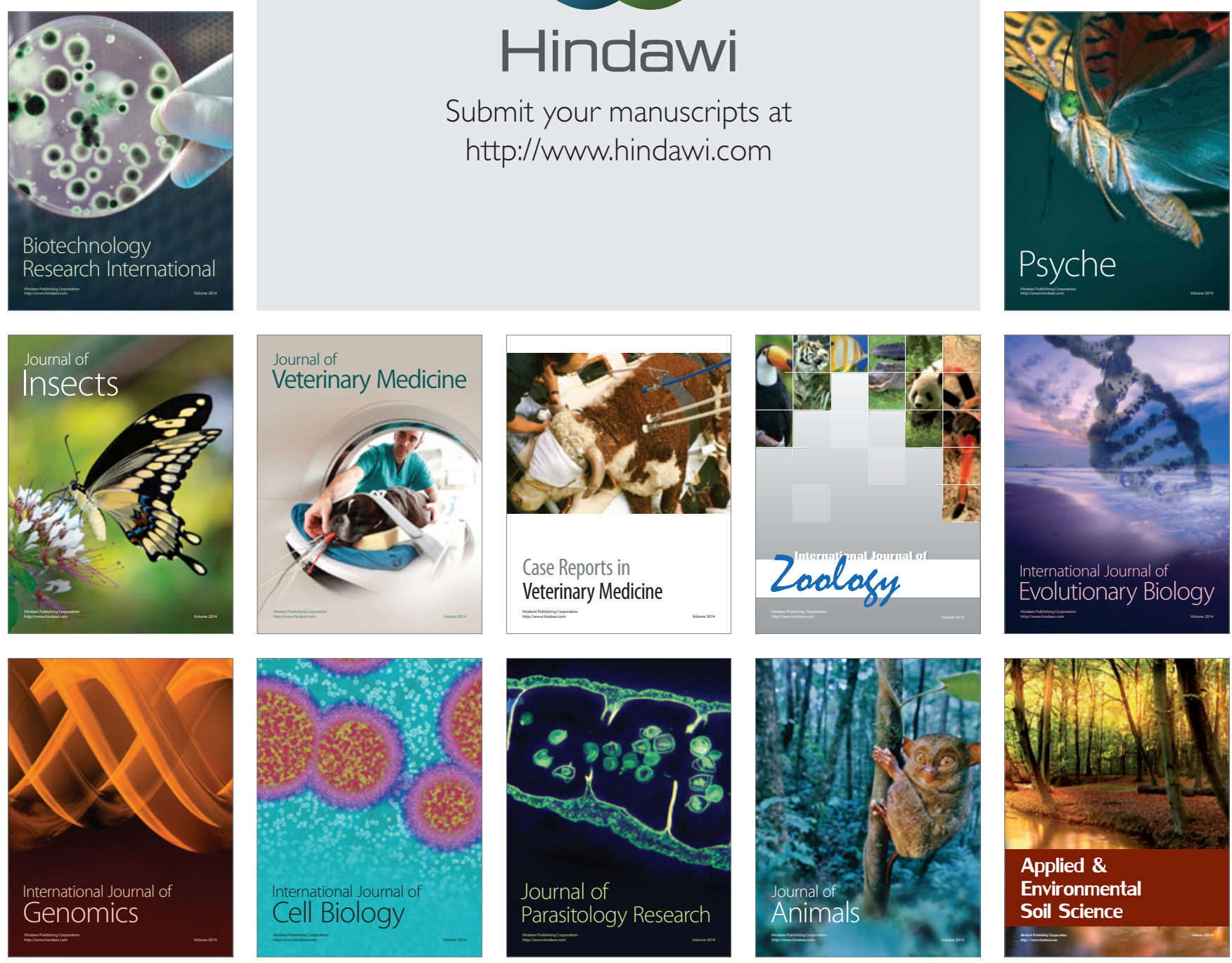